TWO HUNDRED POUNDS REWARD FOR A DISCOVERY.

To the Editor of The LANCET.

SIR:-There is one branch of medical science well deserving of the closer attention of the profession, and which has, I think, been rather neglected, namely, the dissolution of calculi in the kidney and bladder, more particularly in the latter. Probably this might soon be effected if proper experiments were made; and, considering the very great prevalence of calcareous complaints, such discovery is a great desideratum. Crushing and extraction are operations which are only applicable to stones of certain magnitude, while the chief difficulty lays with the small calculi, and debris of large stones, after crushing. I regret not to be rich enough to offer a proportionate reward for such discovery; but, as a very humble individual and a sufferer, I am willing to place 200l. at the disposal of any proper persons, to be pair to the discoverer of such a solvent. As a further stimulus to exertion, the experimentalist must bear in mind the certainty of the enormous remuneration to be derived from the numerous sufferers among the rich, who would give thousands of pounds (in many cases) for relief. Let him also consider the internal satisfaction which he would experience as one of the greatest benefactors of the human race, and on the honour and immortal renown which such discovery would infallibly confer upon him; and, though last, yet not least, let him reflect on the blessing of the good God on him for his charitable exertions.

Pray, Sir, have the gastric juices of divers animals ever been tried in the form of injection? Gastric juice quickly dissolves most things. Your obedient and humble servant,

26, Southampton-street, Strand.

$$
\text { F. ScorT. }
$$
April 5, 1838.

*** Gastric juice has never, we believe, been applied as a solvent to metallic, earthy, or other inorganic substances, nor do we see any reason for supposing that it would produce any effect on them.-ED. L.

\section{CORONER'S INQUESTS. VERDICTS WITHOUT MEDICAL EVIDENCE.}

\section{To the Editor of The Lancet.}

SIR:-Since the passing of the late Act relative to the payment of medical witnesses summoned to inquests, you cannot but have observed the absurd and iniquitous verdicts resulting from deficiency of medical evidence. It seems to me a most preposterous thing that a jury, totally ignorant of the subject, should be allowed to pronounce such a verdict as the following:-" The child was suffocated in the birth for want of assistance ; and great blame attaches to Mr. Barton, a medical pupil of Brownlow-street Hospital, for not attending to the case after having been twice sent for,"

It is incredible that the above verdict is going the round of the papers, having been pronounced by a jury in Monmouth-street, Seven Dials, without the least professional evidence to guide their ignorance. Thus through the no doubt honest ignorance $0_{s}$ the jury and the malevolence of reporters, whose silence I refused to bribe, feeling conscious of no neglect of duty, I am held up to the world as having been the cause of the death of the child. I was under no obligation to attend the woman but such as might arise from $m y$ own private charity. When application was made to me, being engaged, I sent them to a neighbouring licentiate, who received no call from them, Soon as disengaged I hastened to the house. according to the direction given me little more than two hours previously, but was there informed that no person of that name, nor a woman lying-in, dwelt in the house. These statements were made at the inquest, where I was told that a wrong direction had been given to me. With respect to the being twice sent for, a little girl, apparently six or seven years of age, came first, to whom I gave the written address of the said licentiate, residing in a neighbouring street. In about five minutes another messenger came, not having applied to the gentleman as directed. He, indeed, never received an application, but the parish midwife, after some delay, was called in, not, however, before the child was born. The father, who is entitled to two guineas from a club on the birth of each of his children, came to me two days after the inquest, with a view to extort money, and asserted positively that the child was crying "for two hours." This he said in order to prove his right to the two guineas, which the club withheld, they requiring proof that it was born alive. The absurdity of the former part of the verdict requires not to be pointed out to any one at all conversant with the subject, the labour having been quick and easy, and the woman doing well.

By directing the attention of the public to this infamous pronouncing of verdicts without medical evidence, by which the mass of hearers may be misled, you cannot fail of obliging all your readers, and none more so than, Sir, your obedient servant,

Thomas Barton,

British Lying-in Hospital, Brownlow-street, Long Acre,

April 13, 1838. 